\title{
An empirical model for analysing and interpreting ventricular measures
}

\author{
Campbell Clark, Randy Marbeck, David Li
}

\begin{abstract}
Given the abundant and, at times, contradictory studies of ventricular enlargement in neurological and psychiatric disorders, the current study was carried out to provide an empirical basis for analysing and interpreting these measures. A sample of CT scans on 100 control subject was drawn from the files of the University of British Columbia Department of Radiology and 19 measures of ventricular and head diameter or area were made. The interrelationships of these measures were then examined using factor analytic procedures. Three ventricular dimensions were found. To validate these three dimensions, the relationship of each with age was examined and then the agecorrected scores of seven clinical groups were compared on each of these dimensions. The magnitude of the relationship between these dimensions and age was impressive and each dimension contributed unique information regarding these age-related changes. Moreover, the analysis of the clinical groups suggested that differential patterns of ventricular change were present dependent upon the disease. These results are discussed with a view to integrating the findings of previous studies and planning future studies.
\end{abstract}

As the human brain ages, characteristic structural changes occur that are considered normal or at least expected. When these changes happen faster than expected, this accelerated rate of change may indicate the presence of a pathological process. With introduction of high resolution cranial computed tomography, it is possible to estimate ventricular area or diameter and hence infer possible enlargement. Besides dilatation of the ventricular system in, for example, hydrocephalus, ventricular enlargement may also indicate loss of white matter or cortical atrophy. Accordingly, there have been a great number of studies examining ventricular changes in normal and diseased subjects. However, there are still measurement and methodological issues that should be examined.

Bird, ${ }^{1}$ in his review, concluded "of course, most of the studies so far carried out may have measured the wrong parameters", whereas Boronow et $a l^{2}$ argue: “ 'atrophy' is a global description whose component parts of VBR (ventricular brain ratio), cortical sulci, third ventricle and cerebellar vermis have not yet been shown to be interrelated". These comments reflect in part the ongoing debates resulting from contradictory reports in the literature on ventricular changes in different diseases. For example, Boronow et al found third ventricle atrophy in patients with schizophrenia while earlier studies had reported dilation of the paired lateral ventricles. ${ }^{3-5}$

The first purpose of this study was to discover if different measures of ventricular area or diameter provide similar or different information on ventricular enlargement. Therefore, 13 measures of ventricular area or diameter (nine area and four linear measures) and six measures of head area or diameter (three linear and three area measures) derived from the CT scans of 100 normal subjects aged 18 to 79 were factor analysed to find out the number of ventricular dimensions underlying these measures. As many studies in the literature report a strong relationship between age and different measures of ventricular system, ${ }^{6-9}$ the second purpose of the study was to discover the relationship between age and different ventricular measures. The primary question was whether specific measures provided unique information on the normal ventricular changes with ageing. This question was addressed by predicting age from the 13 ventricular measures using a step-wise multiple regression analysis.

The final purpose of the current study was to validate these dimensions clinically by determining if unique profiles of ventricular change were present in different neurological and psychiatric conditions. These specific measures for each ventricular dimension as identified by factor analysis were used to generate regression equations predicting the age of the normal subjects and these regression equations were used to predict age in the clinical groups. The residuals or the number of years their predicted age differed from their actual age were then analysed using analysis of variance procedures to see if different disorders had characteristic profiles of abnormal ventricular enlargement. The patient sample consisted of 70 patients representing seven diagnostic categories, as follows: 1) dementia of unknown origin; 2) multiple sclerosis; 3) Parkinson's disease; 4) Huntington's chorea; 5) temporal lobe epilepsy; 6) schizophrenia; and 7) unipolar depression with melancholia. These diagnostic categories were selected because ventricular enlargement has been reported for each category. ${ }^{10}$

\section{Methods}

Sample selection and characteristics

The normal sample was drawn from the Department of Radiology files of subjects where the indication for a CT scan was either intractable headache or possible cerebral 
trauma and no abnormalities were identified on the CT examination. The files were reviewed until 100 subjects were identified who met these criteria. The resulting sample consisted of 44 women and 56 men with a mean age of 42.0 ( $S D=17 \cdot 4$; range $18-79$ ). In addition, the CT scans for seven neurological/ psychiatric diagnostic categories, namely dementia of unknown origin, Parkinson's disease, Huntington's chorea, multiple sclerosis, temporal lobe epilepsy, schizophrenia and unipolar depression with melancholia were drawn from the files.

The diagnosis of dementia was made based on the patient's history and clinical presentation. The mean age of this group was 69.6 (range 47 to 84 ) and consisted of nine males and four females $(n=13)$. The diagnosis of Parkinson's was based on clinical presentation. The mean age of this group was 65.9 (range 50-82) and consisted of five males and four females $(n=9)$. The diagnosis of Huntington's chorea was based on a positive family history and clinical presentation of chorea. The mean age for this group was 33.7 (range 19-58) and consisted of six males and five females $(n=11)$. The diagnosis of temporal lobe epilepsy was based on a verified seizure history and an appropriate electroencephalographic study. The mean age of this group was 33.6 (range 13 to 80 ) with five males and five females. The diagnosis of multiple sclerosis was based on the criteria for clinically definite MS. ${ }^{11}$ The mean age of this group was 57.3 (range 27 to 80 ) and consisted of four males and seven females $(n=11)$. The two psychiatric diagnoses of depression and schizophrenia were based on the respective DSM-III criteria confirmed by two independent psychiatrists. ${ }^{12}$ The mean age for the patients with schizophrenia was 31.6 (range 20 to 51) and consisted of five males and two females $(\mathbf{n}=7)$. The mean age for the depressed subjects was 52.8 (range 27 to 70 ) and consisted of five males and four females ( $n$ $=9$ ).

\section{CT scanning procedures, slice selection and measurement procedures}

All CT scans were done on a Siemens Somatom DR2 whole body scanner with a slice thickness of $8 \mathrm{~mm}$ and slice interval of $8 \mathrm{~mm}$. Twelve to 14 contiguous slices were obtained at an angle of $20^{\circ} \mathrm{C}$ to the canthomeatal line. From these slices, three were selected where 1) the temporal horns of the ventricle system were best visualised; 2 ) the frontal horns were best visualised and 3) the body of the paired lateral ventricles were the largest. These images were then enlarged to life size and the ventricles and edge of the brain were outlined on a sheet of tracing paper. The resulting montages were digitised so that area and linear measurements could be made with a high degree of accuracy. The largest transverse intra-cranial diameter and the total brain area were estimated for each of the three slices. The linear measures of the ventricle system were the width of the lateral ventricles, bifrontal span, caudate span and width of the third ventricle. The area measurements were the right and left areas of frontal horns, lateral ventricles, occipital and temporal horns as well as the area of the third ventricle. These measurements are illustrated in fig 1 .

Although a single rater was used in this study, intrarater and method reliability was determined by repeating the above procedures on six scans drawn from the first twenty reviewed. The lowest test/retest correlation for the 19 measures was 0.93 (area of left temporal horn). Given the magnitude of this correlation and the fact that measurement error would only reduce the magnitude of effect in subsequent analyses, the method was deemed to be reliable. As some of the patients were rescanned at later dates (six months to three years), six of these scans were selected to determine test/retest reliability. In this case, the lowest correlation was $\mathbf{0 . 8 4}$. These correlations may be reduced by different positioning of the head on the second scan or differential disease and ageing processes. However, again the results indicate that these are reliable estimates.

\section{Analyses}

To ensure that the distribution of each ventricular measure for the control subjects could be assumed to be normal, each distribution was compared with the normal distribution by means of the Kolmogorov-Smirnov test. ${ }^{13}$ None of the distributions differed significantly from the normal distribution and hence, parametric analyses were appropriate. Therefore, the nineteen ventricular and brain measures for the normal subjects were factor analysed using a principle component analysis with a varimax rotation. The number of factors retained was determined by the KaiserGuttman rule (that is, eigenvalues $>1 \cdot 0 .^{14}$ From this analysis, it is possible to determine if the brain and ventricular measures are independent and whether different ventricular measures provide unique information. Subsequently, each of the thirteen ventricular measures was standardised by dividing the ventricle measure by the slice appropriate linear or area brain measurement. This stan-

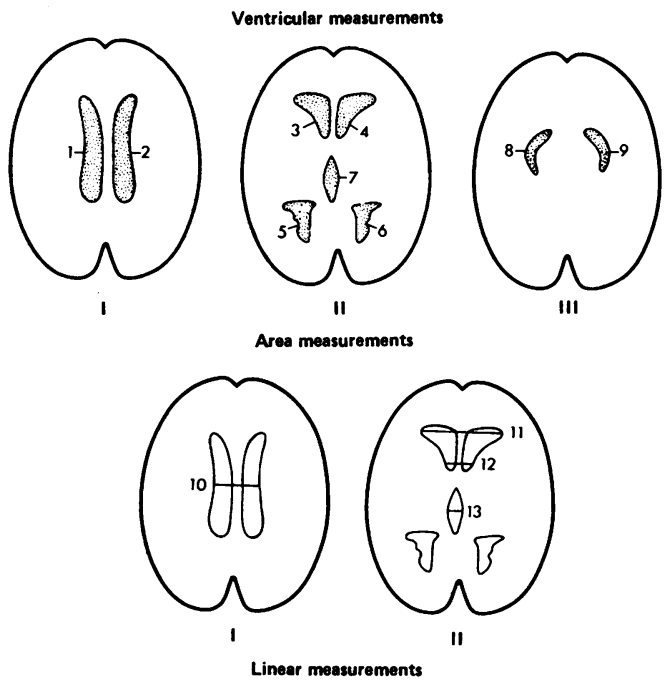

Figure 1 Area measurements: 1, 2 left and right paired lateral ventricles; 3, 4 left and right frontal horns; 5, 6 left and right occipital horns; 7 , third ventricle; 8 , 9 left and right temporal horns. Linear measurements: 10, width of lateral ventricles; 11, bifrontal span; 12, caudate span; 13, width of third ventricle. 
dardisation was done so that the dependent variables would be similar to previous studies. These thirteen measures were used as predictors of age in a step-wise multiple regression analysis ( $F$ to enter $-p \leqslant 0.05 ; F$ to remove $-p \geqslant 0 \cdot 10)$. This analysis yields an estimate of the magnitude of relationship between age and the different ventricular measures. From this analysis, it is also possible to determine whether ventricular enlargement with age is a unitary process or different ventricular measures provide unique information regarding this process.

The purpose of the last analysis strategy was to determine if there were characteristic patterns of ventricular change in different disease states. To accomplish this, three separate regression equations were generated based on the factors found in the factor analysis. As three distinct ventricular factors were found, the variables that loaded highly on each factor were included in the respective regression analyses. Using each of these equations, a predicted age was computed for each patient on each of the three factors. This predicted age was then subtracted from the patient's actual age to produce a residual or the number of years that age was either under- or over-estimated by the regression equation. A negative residual indicates that the ventricular measures are larger than expected for a subject of that age. Therefore, if a 35 year old patient had a residual score of 20 years, the actual ventricle measurements was comparable to a 55 year old normal subject. These residuals were then analysed using an analysis of variance procedure with diagnosis as the between group factor and the residuals for the three ventricular analyses as the repeated measure.

\section{Results}

Principal component factor analysis

The results of the principal component analysis with a varimax rotation are summarised in table 1. The four factor solution included $75.7 \%$ of the total variance (respective eigenvalues = $9 \cdot 20,2 \cdot 78,1.31$, and 1.09). The first finding of import is that the six brain measures all loaded on the same factor (factor II) and no ventricular measure loaded on this factor. Because three factors were defined by ventricular measures, it is apparent that there is more than one dimension in the enlargement of the ventricular system and hence, different measures do provide different information. The area of the frontal horns and third ventricle as well as all the linear ventricle measures loaded on factor I while factor III was defined by the area of the lateral ventricles and the occipital horn. Factor IV was defined by the area of the temporal horns. From this analysis, it is clear that in normals some measures were highly related. However, measures that one would expect intuitively to be highly related were not. For example, the width of the lateral ventricles and their area were defined by different factors.

\section{Multiple regression analysis predicting age}

In table 2, the correlation between the ventricle measures and age are given for each step of the multiple regression analysis. From this table, it is apparent that each measure was significantly correlated with age (that is, first order correlations) and that the magnitude of these correlations decreased considerably as each variable entered into the regression equation. In addition, for clinical reference, the means, standard deviations and amount of change per year are given for each of the measures in table 2 . The results of the regression analysis are presented in table 3. Three variables were selected based on the magnitude of their correlations with age and the unique variance accounted for by each. The variables were caudate span, the area of right lateral ventricle and the area of the left temporal horn. The multiple correlation coefficient was 0.72 hence $52 \%$ of the variability in the subjects' ages was accounted by these three ventricular measures. Therefore, one may infer that the ventricles enlarge in a systematic manner with advancing age. In addition, it is important to note that one measure from each of the three ventricular factors was selected for inclusion in this analysis. This finding further validates the three dimensions identified in the factor analysis as being unique aspects of the ventricular system.

Table 1 Factor loadings and communality estimates of ventricular measurements for the Varimax rotation

\begin{tabular}{|c|c|c|c|c|c|c|}
\hline & & $I$ & $I I$ & III & $I V$ & Communalities \\
\hline $\begin{array}{l}\text { Factor I } \\
\text { Area } \\
\text { Linear }\end{array}$ & $\begin{array}{l}\text { Frontal horn left } \\
\text { Frontal horn right } \\
\text { Third ventricle } \\
\text { Width of lateral ventricle } \\
\text { Bifrontal span } \\
\text { Caudate span } \\
\text { Width of third ventricle }\end{array}$ & $\begin{array}{l}0.73 \\
0.74 \\
0.74 \\
0.69 \\
-0.77 \\
0.76 \\
0.76\end{array}$ & $\begin{array}{l}0.29 \\
0.23 \\
0.08 \\
0 \cdot 19 \\
0.24 \\
0.19 \\
0.08\end{array}$ & $\begin{array}{l}0.39 \\
0.32 \\
0.26 \\
0.31 \\
0.17 \\
0.30 \\
0.32\end{array}$ & $\begin{array}{r}0.15 \\
0 \cdot 18 \\
0.35 \\
-0.12 \\
0.00 \\
0.30 \\
0.35\end{array}$ & $\begin{array}{l}0.79 \\
0.73 \\
0.74 \\
0.63 \\
0.69 \\
0.79 \\
0.80\end{array}$ \\
\hline $\begin{array}{l}\text { Factor II } \\
\text { Area } \\
\text { Linear }\end{array}$ & $\begin{array}{l}\text { Total brain area } 1 \\
\text { Total brain area } 2 \\
\text { Total brain area } 3 \\
\text { Intracranial diameter } 1 \\
\text { Intracranial diameter } 2 \\
\text { Intracranial diameter } 3\end{array}$ & $\begin{array}{r}-0.10 \\
0.04 \\
0.38 \\
0.35 \\
0.24 \\
0.28\end{array}$ & $\begin{array}{l}0.86 \\
0.87 \\
0.45 \\
0.84 \\
0.84 \\
0.74\end{array}$ & $\begin{array}{r}0.34 \\
0.34 \\
0.10 \\
-0.03 \\
0.03 \\
-0.04\end{array}$ & $\begin{array}{r}0.07 \\
-0.03 \\
0.16 \\
0.01 \\
0.05 \\
0.13\end{array}$ & $\begin{array}{l}0.87 \\
0.87 \\
0.38 \\
0.83 \\
0.76 \\
0.64\end{array}$ \\
\hline $\begin{array}{c}\text { Factor III } \\
\text { Area }\end{array}$ & $\begin{array}{l}\text { Lateral ventricle left } \\
\text { Lateral ventricle right } \\
\text { Occipital horn left } \\
\text { Occipital horn right }\end{array}$ & $\begin{array}{l}0.48 \\
0.48 \\
0.36 \\
0.35\end{array}$ & $\begin{array}{l}0.17 \\
0.13 \\
0.14 \\
0.10\end{array}$ & $\begin{array}{l}0.75 \\
0.72 \\
0.80 \\
0.76\end{array}$ & $\begin{array}{l}0.17 \\
0.26 \\
0.15 \\
0.27\end{array}$ & $\begin{array}{l}0.86 \\
0.84 \\
0.82 \\
0.78\end{array}$ \\
\hline $\begin{array}{c}\text { Factor IV } \\
\text { Area }\end{array}$ & $\begin{array}{l}\text { Temporal horn left } \\
\text { Temporal horn right }\end{array}$ & $\begin{array}{l}0.15 \\
0.19\end{array}$ & $\begin{array}{l}0.12 \\
0.04\end{array}$ & $\begin{array}{l}0.22 \\
0.19\end{array}$ & $\begin{array}{l}0.82 \\
0.85\end{array}$ & $\begin{array}{l}0.76 \\
0.79\end{array}$ \\
\hline
\end{tabular}


Table 2 Means, standard deviation and regression results for 13 ventricular measures

\begin{tabular}{|c|c|c|c|c|c|c|c|}
\hline \multirow[b]{2}{*}{$\begin{array}{l}\text { Factor } I \\
\text { Area }\end{array}$} & \multirow[b]{2}{*}{$\begin{array}{l}\text { Frontal horn left } \\
\text { Frontal horn right } \\
\text { Third ventricle } \\
\text { Width of lateral ventricle } \\
\text { Bifrontal span } \\
\text { Caudate span } \\
\text { Width of third ventricle }\end{array}$} & \multicolumn{2}{|c|}{$\bar{X}(S D)^{1}$} & \multirow{2}{*}{$\begin{array}{c}\begin{array}{l}m m \text { or } \\
m^{2} / y r\end{array} \\
10.0 \\
10.9 \\
5.2 \\
0.9 \\
0.7 \\
0.3 \\
0.2\end{array}$} & \multicolumn{3}{|c|}{$\begin{array}{l}\text { Correlations with age after each step of } \\
\text { regression }\end{array}$} \\
\hline & & $\begin{array}{r}268 \cdot 8 \\
248 \cdot 9 \\
138 \cdot 8 \\
27 \cdot 9 \\
36 \cdot 7 \\
14 \cdot 3 \\
5 \cdot 2\end{array}$ & $\begin{array}{r}(142) \\
(135) \\
(93) \\
(6 \cdot 8) \\
(5 \cdot 3) \\
(4 \cdot 8) \\
(2 \cdot 7)\end{array}$ & & $\begin{array}{l}1 \\
0 \cdot 56^{\star \star \star} \\
0 \cdot 46^{\star \star \star} \\
0 \cdot 55^{\star \star \star} \\
0 \cdot 34^{\star \star} \\
0 \cdot 39^{\star \star \star} \\
0 \cdot 67^{\star \star \star} \\
0 \cdot 56^{\star \star \star}\end{array}$ & $\begin{array}{r}2 \\
0.18 \\
0.02 \\
0.13 \\
-0.04 \\
0.04 \\
\overline{0.13}\end{array}$ & $\begin{array}{r}3 \\
0.09 \\
-0.09 \\
0.05 \\
-0.10 \\
-0.01 \\
-\overline{0.01}\end{array}$ \\
\hline $\begin{array}{l}\text { Factor III } \\
\text { Area }\end{array}$ & $\begin{array}{l}\text { Lateral ventricle left } \\
\text { Lateral ventricle right } \\
\text { Occipital horn left } \\
\text { Occipital horn right }\end{array}$ & $\begin{array}{l}825 \cdot 2 \\
809 \cdot 8 \\
318 \cdot 7 \\
295 \cdot 3\end{array}$ & $\begin{array}{l}(428) \\
(418) \\
(224) \\
(201)\end{array}$ & $\begin{array}{l}31 \cdot 1 \\
28 \cdot 3 \\
17 \cdot 3 \\
12 \cdot 5\end{array}$ & $\begin{array}{l}0 \cdot 61^{\star \star \star} \\
0 \cdot 63^{\star \star \star} \\
0.53^{\star \star \star} \\
0.55^{\star \star \star}\end{array}$ & $\begin{array}{l}0 \cdot 30^{\star \star} \\
0 \cdot 32^{\star \star} \\
0 \cdot 24^{\star \star} \\
0 \cdot 25^{\star \star}\end{array}$ & $\begin{array}{l}0.09 \\
\overline{0.13} \\
0.13\end{array}$ \\
\hline $\begin{array}{l}\text { Factor IV } \\
\text { Area }\end{array}$ & $\begin{array}{l}\text { Temporal horn left } \\
\text { Temporal horn right }\end{array}$ & $\begin{array}{l}122 \cdot 5 \\
128 \cdot 1\end{array}$ & $\begin{array}{r}(104) \\
(97)\end{array}$ & $\begin{array}{l}5 \cdot 9 \\
6 \cdot 5\end{array}$ & $\begin{array}{l}0 \cdot 41^{\star \star \star} \\
0 \cdot 38^{\star \star \star}\end{array}$ & $\begin{array}{l}0 \cdot 19^{\star} \\
0 \cdot 15\end{array}$ & $\begin{array}{l}0 \cdot 16^{\star} \\
0 \cdot 12\end{array}$ \\
\hline
\end{tabular}

${ }^{\star} p \leqslant 0.05 ;{ }^{\star \star} p \leqslant 0.01 ;{ }^{\star \star \star} p \leqslant 0.001$.

'Area measurements are $\mathrm{mm}^{2}$; linear measurements are $\mathrm{mm}$

Table 3 Stepruise multiple regression using CT variables to predict age

\begin{tabular}{llrrrrrr}
\hline Entry & Variable & $S S$ & df & ms & F-value & $R$ & $R^{2}$ \\
\hline 1 & Caudate span & 12,749 & 1 & 12,749 & $83 \cdot 1^{\star \star \star}$ & 0.67 & $0 \cdot 44$ \\
2 & Ventricle body right & 1,768 & 1 & 1,768 & $11^{\star \star}$ & $0 \cdot 32$ & 0.06 \\
3 & Temporal horn left & 728 & 1 & 728 & $4 \cdot 7^{\star}$ & $0 \cdot 20$ & 0.02 \\
Total error & & 15,246 & 3 & 5,082 & $33 \cdot 1 \star \star \star$ & 0.72 & 0.52 \\
& & 14,718 & 96 & 153 & & & \\
\hline
\end{tabular}

${ }^{\star} p \geqslant 0.05 ;{ }^{\star \star} p \geqslant 0.01 ;{ }^{\star \star \star} p \geqslant 0.001$

For the profile of residuals for each of the clinical groups, the analysis of variance of the residuals yielded a significant between diagnosis effect $\left(F_{7,162}=16 \cdot 5, p \leqslant 0.001\right)$ and a significant interaction between diagnosis and the ventricular dimensions. $\left(F_{14,324}=3 \cdot 6, p \leqslant\right.$ 0.001 ). The actual mean residuals for the three factors (that is, I, III and IV) are plotted by diagnosis on figure 2 . By definition, the mean of the residuals for the normal group is zero for each factor (Standard Error of Mean $=1.29$, 1.32 and 1.59 respectively). From this figure it is apparent that for these samples of demented and Parkinsonian patients, there is no evidence of ventricular enlargement as their predicted ages were on average less than their actual ages. The depressed subjects had evidence of ventricular enlargement on Factor III while the multiple sclerosis group had evidence of ventricular enlargement on Factors I and III.

For the patients with temporal lobe epilepsy, the patients with schizophrenia and the patients with Huntington's chorea, there was evidence of ventricular enlargement on all three measures but the groups differed in terms of magnitude and pattern of enlargement. Given the small sample sizes, the possibility of non-normal distributions within specific categories and the potential influences of other disease-related variables (for example, duration, treatments), prevents generalisation of these results to the specific diagnostic categories. However, with the exception of patients with dementia and Parkinson's disease, the figure clearly indicates that in different clinical conditions, there are different profiles of ventricular enlargement.

\section{Discussion and conclusions}

In a recent review, Shelton et al ${ }^{15}$ stated that there are over 90 published articles examining ventricular changes in patients with schizo- phrenia while McGeer, ${ }^{16}$ in a selective review of ventricular changes in dementia, cites 17 articles. Because of the sheer volume of these studies, as well as the presence of contradictory findings, the current study was undertaken to determine: 1) the number of dimensions underlying normal ventricular structure; 2 ) the relationship of these dimensions with normal ageing; and 3) whether differential profiles of

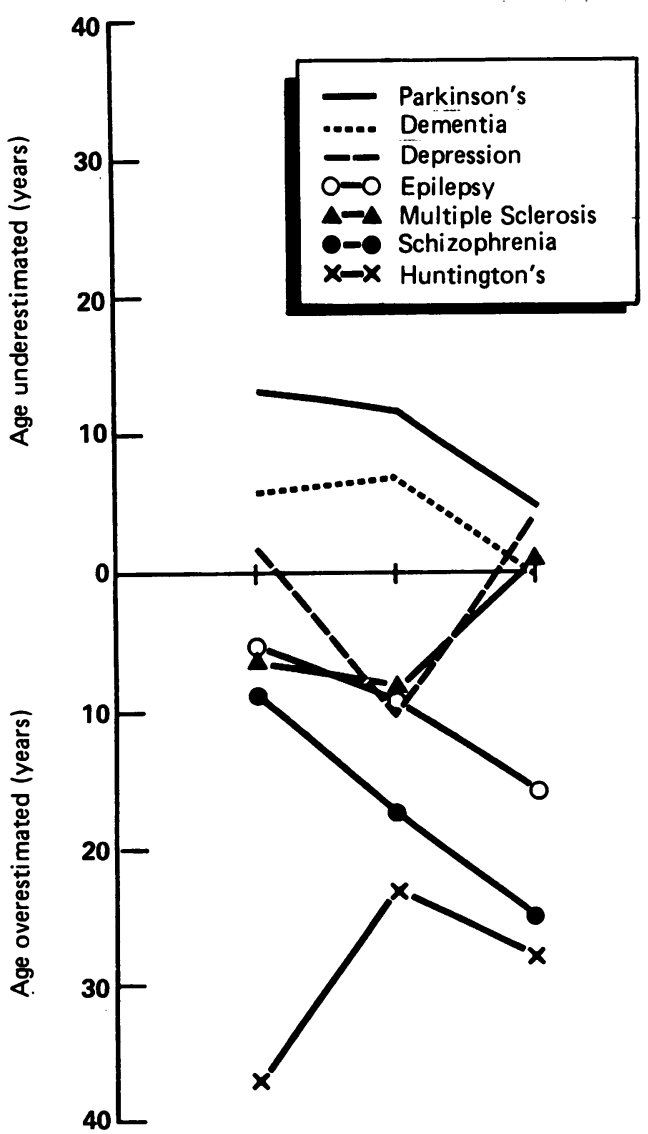

Figure 2 The mean residual scores for the seven clinical groups on Factors $I, I I I$ and IV. 
ventricular enlargement were evident in different diagnostic categories. From these analyses, a model can be evolved for comparing and integrating the findings of different studies. Before reviewing the findings, it should be noted that the normal subjects in this study were not a representative normal sample. Rather, they were selected patients for whom no eventual anatomical abnormalities were identified on the CT but who nevertheless presented with either headaches or a history of cerebral trauma. Even if there was an undiagnosed neuropathological process it could only reduce: 1 ) the inter-measure correlations in the factor and age analyses, and 2) the between group differences in the multivariate analysis of the clinical groups. Therefore, this selection process may result in less powerful findings but should not produce spurious correlations or differences.

The results of the factor analysis suggest that there are at least three aspects of ventricular enlargement in the linear and area measures. This finding may provide a model for determining truly equivalent or contradictory results in the clinical literature. For example, if studies using one of the measures loading highly on factor I (table 1) found significant differences between an affected sample and a control group whereas studies employing ventricular measures loading highly on factors III or IV did not report these differences, these studies should not be considered as contradictory. Rather, because the studies with positive findings measured one ventricular domain whereas the studies with negative findings measure another, there is no inherent contradiction, only evidence of selective or restricted ventricular changes. The factor analytic procedure permits the identification of these domains such that a theoretical model can be evolved for comparing different studies. However, before employing such a model, the actual domains or factors identified in this study should be replicated.

The multiple regression analysis of age is of interest for two reasons. The first is that the first order correlation coefficients were all statistically significant and in the main consistent with previous studies. ${ }^{6-9}$ The actual magnitude of the multiple correlation coefficient was impressive $(R=0.72)$, suggesting that ageing is a primary determinant of ventricular changes. The second reason is that each of the three predictors selected to generate this multiple regression coefficient represented one of the three ventricular factors identified in the factor analysis. This finding provides further validation of three different aspects in ventricular enlargement.

The multivariate analysis of variance was done for two reasons. The first was to illustrate that the multiple regression and factor analytic procedures could be employed to reduce the number of dependent variables from 13 to three and control statistically for the known effects of age. By using the normal data, one can estimate a predicted age for each patient and determine whether this estimate is less or greater than the patients actual age. This procedure is statistically far more powerful than age matching because the actual variation expected with normal ageing is removed, rather than controlled for. When there is as strong a relationship as shown here and reported previously, one should capitalise on the statistical advantage by removing the systematic source of variability. The second purpose was to illustrate that different patient groups do have different patterns of ventricular enlargement. Although the actual sample sizes of each of the clinical groups is small and pertinent clinical variables were not considered, the significant group by measure interaction effect suggests that ventricular changes are differential and in part dependent upon the patient's diagnosis. The plot of the group mean residuals in fig 2 illustrates the unique profiles found for the clinical groups on the three aspects of ventricular enlargement. With the exception of the patients with dementia, the results are consistent with other studies despite the small sizes and lack of control of potential nuisance variables. However, given the small sample size and selection criteria, direct clinical inferences from these results should not be drawn.

In conclusion, this study attempts to delineate an empirical model for improved understanding of ventricular changes in normal and abnormal samples. This model may be applied retrospectively to previous studies of ventricular enlargement by providing a framework for interpretation or prospectively, for planned studies, to maximise the probability of positive, interpretible findings.

Mr Marbeck was supported as part of the summer research programme for medical students at the University of British Columbia. Dr Clark is a BCHCRF scholar.

1 Bird JM. Computerized tomography, atrophy and dementia: a review. Progress in Neurobiology 1982;19:91-115.

2 Boronow J, Pickar D, Ninan PT, Roy A, Hommer D, Linnoila M, Paul SM. Atrophy limited to the third ventricle in chronic schizophrenic patients. Arch Gen ventricle in chronic schizo
Psychiatry 1985;42:266-71.

3 Johnstone EC, Crow TJ, Frith CD, Husband J, Kreel L. Cerebral ventricular size and cognitive impairment in chronic schizophrenia. Lancet 1976;ii:924-6.

4 Nasrallah HA, Jacoby CG, McCalley-Whitters $M$ Kuperman $S$. Cerebral ventricular enlargement in subtypes of chronic schizophrenia. Arch Gen Psychiatry 1982, 39:774-7.

5 Weinberger DR, Fuller Torrey E, Neophytides AN, Wyatt RJ. Lateral cerebral ventricular enlargement in chronic schizophrenia. Arch Gen Psychiatry 1979;36:735-9.

6 Jacoby RJ, Levy R, Dawson JM. Computer tomography in the elderly: the normal population. Brit J Psychiatry 1980;136:249-55.

7 Hughes CP, Gado $M$. Computer tomography and aging of the brain. Radiology 1981;139:391-6.

8 Takeda S, Matsuzawa T. Brain atrophy during aging: a quantitative study using computed tomography. Journal quantitative study using computed tomography.

9 Laffey PA, Peyster RG, Nathan R, Haskin ME, McGinley JA. Computed tomography and aging: results in the normal elderly population. Neuroradiology 1984;26: 273-8.

10 Jaskiw GE, Andreasen NC, Weinberger DR. X-ray computed tomography and magnetic resonance imaging in psychiatry. In: Hales R, Frances A, eds. APA Annual Review Vol 6. Washington, DC: American Psychiatric Press, 1987:260-99.

11 Poser CM, Paty DW, Scheinberg L, et al. New diagnostic criteria for multiple sclerosis: guidelines for research protocols. Ann Neurol 1983;13;3:227-31.

12 Diagnostic and Statistical Manual of Mental Disorders. Third Ed. Washington, DC: American Psychiatric Association, 1980.

13 Kraft C, van Eiden C. Nonparametric introduction to statistics. New York: MacMillan, 1968.

14 Gorsuch R. Factor Analysis. Philadelphia: Saunders, 1974. BB, Weinberger DR. Cerebral structural pathology in BB, Weinberger DR. Cerebral structural pathology in schizophrenia: evidence for a selective prefr
defect. Am J Psychiatry 1988;145;2:154-63.

16 McGeer PL. Brain imaging in Alzheimer's disease. Br Med Bull 1986;42;1:24-8. 